\section{CASES OF HÆMOPHILIA.}

By CHARLES A. BRIGSTOCKE, EsQ., Calne.

AN account of some cases of hæmophilia, by Dr. J. West Walker, having appeared in the BRITISH MEDICAL JOURNAL of June 8th, perhaps the following case at present under treatment, with the family history, may prove interesting.

H. C., aged 13, a somewhat anæmic but tolerably well nourished boy, had, when born, large extravasations over both shoulders. In a few days after birth, one of the ankles became distended by effusion. When about eight months old, he suffered from such profuse epistaxis that it seemed doubtful whether he could survive the loss of so much blood. Ever since that time, he has suffered at intervals from effusion into the joints. Sometimes the ankles are affected; at other times the knees, and sometimes the elbows or wrists; the effusion not even sparing the small joints of the fingers and toes. He also suffers from extravasations of blood over different portions of the cutaneous surface, produced at times by very trivial causes, and sometimes occurring in an apparently spontaneous manner. A short walk will frequently produce discoloration of the calves of the legs. The affected joints are, during the attacks, the seat of acute pain, and are somewhat discolored; the pain at times even produces delirium; and the effusion lasts sometimes for weeks, although the pain subsides. He has had no hæmaturia, hæmoptysis, or hæmatemesis, and has apparently no organic disease. He has been vaccinated, and has had measles. About a twelvemonth ago, such profuse hæmorrhage followed the extraction of a tooth that he lost a considerable quantity of blood before medical assistance could be procured. At present the left knee and left elbow are the joints affected. His appetite is good; the bowels regular ; there is no albumen in the urine.

A brother, H. C., aged 12, who died about ten years ago from internal hæmorrhage distending the abdomen, had suffered in a precisely similar manner, with the addition of hæmatemesis and hæmaturia. Another brother, A. C., who died twelve years ago, aged $3 \frac{1}{2}$, had suffered almost constantly from epistaxis; and the ostensible cause of death was hæmorrhage from the gums.

There are seven children now alive-three boys and four girls-all of whom are in good health, with the exception of the eldest boy (i.e., the first mentioned case) : the six younger ones have never shown any symptom of the disease. The mother, aged 39, enjoys good health, and has never shown any hæmorrhagic tendency. The father, aged 4I, is rather a weakly man. He suffers from occasional epistaxis, sometimes severely; and nearly lost his life about five months ago though rupture of a varicose vein. The mother's fatber, mother, one brother, and three sisters, died of dropsy. Two sisters are alive in weakly health, and one brother in good health. On the paternal side, the father lived to the age of 76 , the mother died early of consumption, and four brothers are alive in good health.

REMARKS. - In this case, as in the one referred to by Dr. Walker, external applications have appeared worse than useless. Warm fomentations have to some extent alleviated the pain during the onset of attacks. Believing the case to be allied in character to scurvy (at least to some extent), I have given the boy a liberal diet, with fresh vegetables, ripe fruit in moderation, warm clothing, etc. As to medicines, he has been now taking for some time the citrate of iron and quinine, with an excess of citric acid, as well as cod-liver oil. His general health has certainly improved, although the tendency to local effusion still exists.

Recovery after Trephining for Cerebral AbScess.-The operation of making an opening into the dura mater for the relief of intracranial suppuration is one which is rarely successful. A case recorded in the Nashville Medical Fournal by Surgeon J. T. Weeds of the United States Army, in which trephining was successfully performed for cerebral abscess following gun-shot wound, is therefore of interest. After removing a portion of bone nearly an inch to the left of the mesial line, and an inch over the superciliary ridge, the coma from which the patient was suffering still remained unrelieved. On closer examination, the dura mater at that part of the opening nearest the middle line appeared to have a bluish tinge, and to bulge a little more than natural; and he imagined that he detected obscure fluctuation. $\mathrm{He}$, therefore incised the dura mater, and plunged his knife into the brain, giving exit to half an ounce of dark green and somewhat foetid pus. The patient was put to bed with the head and shoulders somewhat elevated, and a refrigerant lotion was applied to the head. After some time, the patient became conscious; not a single unfavourable symptom supervened; the wound healed rapidly; and in a fortnight the patient was convalescent.

\section{REPORTS}

\author{
oF
}

MEDICAL AND SURGICAL PRACTICE IN
THE HOSPITALS OF GREAT BRITAIN.

MIDDLESEX HOSPITAL.

CASE OF ACUTE RHEUMATISM, WITH HEAD-SYMPTOMS AND HIGH TEMPERATURE, SUCCESSFULLY TREATED WITH BATHS.

(Under the care of Dr. Henry Thompson.)

RICHARD L., aged $2 \mathrm{I}$, a pale, delicate, nervous-looking lad, was admitted under Dr. Thompson's care on March 16th, 1872. His father, three brothers, and one sister, were all alive, but not strong. His mother died of consumption, and his grandfather was said to have had gout. The boy himself had always been in feeble health. About ten years ago he had an attack of rheumatism, and since that date he had suffered from shortness of breath on any extraordinary exertion. About two years ago he had a severe cough, with slight hæmoptysis. A week before admission, he experienced pain, accompanied by redness and swelling, in the left foot.

On admission, his pulse was 108, temperature ror deg. There was no definite murmur over the præcordia-only a feebleness and roughness, with deficient accentuation of the first sound. He had pain, redness, and swelling, in the hands and ankles. He was ordered a mixture containing fifteen minims of tincture of perchloride of iron every four hours ; nitre poultices to the affected joints; and five grains of compound soap pill in the night. From this date until March 26th, the pains in the joints were extremely variable, coming and going in the most capricious manner; they were never at any time remarkable for their severity. The chest-complications, however, were severe in the highest degree. The signs and symptoms of pericarditis with large effusion developed rapidly : there was unquestionable evidence of sharp pleurisy and extensive pneumonia on the right side, and evidence enough to arouse the suspicion of a limited pneumonia on the left. During this period, the maximum of the pulse-rate amounted to 120, that of the respirations to 60 , and that of the temperature to $103.3 \mathrm{deg}$. There was no albuminuria. During the same period, two leeches were applied to the right lower ribs, the seat of the pleuritic pain; and two to the præcordia, which was subsequently blistered. The diet was liberal under the circumstances; but no stimulants were administered before the 25th, when four ountes of brandy were allowed.

March 26th. Morning pulse, 126; respirations, 60; temperature, 101.2 deg. Evening pulse, 132 ; respirations, 66 ; temperature, 102 deg. The face was exceedingly pale. The pain in the right side continued; the pain in the joints was entirely gone. His breathing was laboured. The præcordial dulness reached the first interspace; laterally, it extended one inch beyond the mammary line, at the level of the nipple. He was ordered to have one grain and a half of iodide of potassium in a mixture containing senega, carbonate of ammonia, and squills ; two leeches to the painful part of the chest; six ounces of brandy daily; and a sixth of a grain of acetate of morphia to be injected beneath the skin. For diet, he was allowed two pints and a half of milk, two eggs, two pints of strong beef-tea, a custard pudding, and twelve ounces of bread, daily.

March 27th. Morning pulse, 126; respirations, 42 ; temperature, I01.8 deg. Evening pulse, 138 ; respirations, 42 ; temperature, 102 deg. Præcordial friction was audible over the whole of the præcordia. March 29th. Pain had returned to all the joints. Evening temperature, 103.8 deg.; pulse, 138 ; respirations, 48.

March 3oth. He slept ill. He passed urine frequently during the night. The friction-sounds were much subdued. He was ordered a draught containing ether and twelve minims of sedative solution of opium. Morning pulse, 126; respirations, 48 ; temperature, 103.8 deg. Evening pulse, 120 ; respirations, 42 ; temperature, 104.2 deg.

March 3Ist, 10 A.M. He had again slept ill. He wandered a good deal during the night, and continued to wander in the morning. The bowels had been open three times; the motions were ochrecoloured, semi-solid, acid. A profuse red miliary eruption appeared over the whole body. The area of præcordial dulness was slightly diminishing. - I P.M. The temperature, which hitherto had been taken

* The temperature in this case is always referred to the axilla where it is not otherwise specified; and the difference between the temperatures in the rectum and the axilla is always assumed to be Wunderlich's average, seven-tenths of a degree, although it is exceedingly probable that, after removal from the bath, the difference might be much greater. Fortunately, this is of no practical moment for the most part in the calculations given. 